Electromagnetic Waves in the Magnetised Plasma

渡 辺 健 二(大阪市大 原子力) $*$

\title{
§1. Introduction and Summary
}

電磁波の波動Vector $\mathbf{k}$ が外場 $\mathbf{B}_{0}$ と直角をなし、又wave のE vector も $\boldsymbol{B}_{0}$ と垂直 の場合には、入射波が平面波のときに8 P a sma に蹯密波を生じ事情がこみ入つてくることは すでに指摘されている1)。Electron Cyclotron Resonance に関する研究会※゙で も話題に上つて懸念されたことでもある。 そのMechanism という钼点から特に興味を覚えたので、平均操作をほどこした後の BoItzmann Equation から出発して眯密波の考慮をしだ。Dispersion ReIaー tion を導いてみた。その結果、1に比して $\left.\gamma_{\mathrm{e}} \kappa \mathrm{T} \mathrm{e} / \mathrm{m}_{\mathrm{e}} \mathrm{c}^{2}\right)$ の order でしかきかない ことがわからたので、現在実用上考慮する必要はないが Me c han i sm という意味で面白い と思うのでその大略を記すことにする。

\section{§2. Mechan i sm}

ある時刻 $\mathrm{t}$ 飞第 1 圀の様な configuration にあるとすると、wave のEにresponseする current jは $\frac{1}{\omega_{\text {ce }}}$ のorderの時間を考光 ると、Eに平行なるののみならず Eに垂直な所謂 HaIICurrent が出てくる。これは第1図
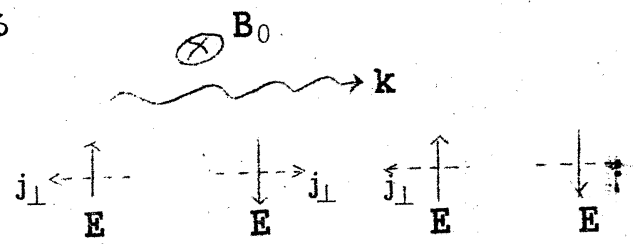

に点線でうよとて、示したが これから明らか な様にcurrent の divergence を示す ことになり空間電荷を生ずる。これは現象論的に

脚註 $※ K$, Watanabe (Institute for Atomic Energy Research, Osaka City. University)

※ L.Spitzer; Physics of Fully Ionized Gases(Interscience, 1956), p. 55 
渡边 健 二

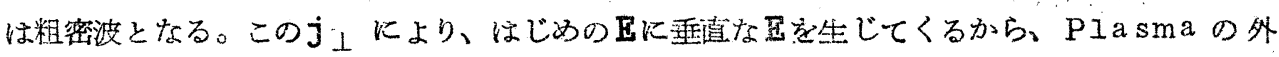
から平面波が入射したときもPIasma 内では平面的でない波として伀播することになる。

§3. Dispersion Relation

第2図の様な confignration で考 える。E，jはミ2の考察から明らかな様 に、 $\mathrm{x}$ -, $\mathrm{y}$ 一成分のみを持つとし又空間的 には簡単のため $\mathrm{y}$ 方向にのみ変化するとす る。(これらの仮定は一般性はそこなわない。) さて波動方程式は通例の如く

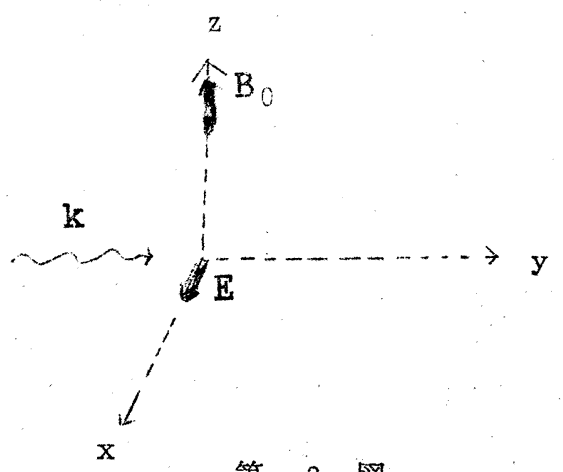

$$
-\nabla \times \nabla \times \mathbf{E}=\frac{1}{\mathrm{c}^{2}} \frac{\partial^{2} \mathbf{E}}{\partial \mathrm{t}^{2}}+4 \pi \frac{\partial \mathbf{j}}{\partial \mathrm{t}}
$$

であり、PIasma 内であるから jは BoItzmann Eq,

$$
\frac{m_{e}}{n_{e} c^{2}} \frac{\partial j}{\partial t}=E+\frac{1}{n_{e} e} \nabla p_{e}-\frac{1}{n_{e} e} j \times B-\eta j
$$

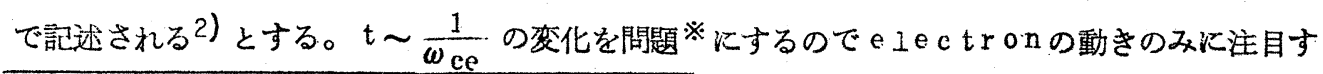
ればよいから、Plasma の mass を支配するEquation は考慮しなくてもよい。記号 etc.はL.Spitzer の教科書 ${ }^{1)}$ としたがう。(但し eとしてはe。m、u.とのま〉を用うる。) 又通例の如く $\mathrm{B}$ は外場の $\mathrm{B}$ 。が交配的であるとし、wave の Bは省略する。

これら(1)(2)式からEとjとのDependenceを求めるのが Me chanism とい5点から重 要な事である。

先づ(1)式を第 2因のconfiguration でxー, y一成分にわけると

$$
\begin{aligned}
\frac{\partial^{2} E x}{\partial y^{2}} & =\frac{1}{c^{2}} \frac{\partial^{2} E x}{\partial t^{2}}+4 \pi \frac{\partial j x}{\partial t} \\
0 & =\frac{1}{c^{2}} \frac{\partial^{2} E y}{\partial t^{2}}+4 \pi \frac{\partial j y}{\partial t}
\end{aligned}
$$

となる。この(4)式によればEy成分は波動方程式に従わないので、外から Exのみを持つ平面波が

脚註 $※$ Ioc. cit., J. 21 
Electromagnetic Waves in the Magnetised Plasma

入射したときP1a sma 内に生ずるEy（これは笑㥙うからきている）篦磁波にならないこと

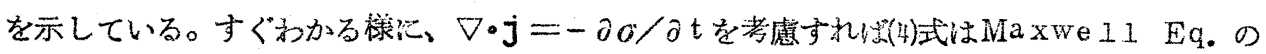

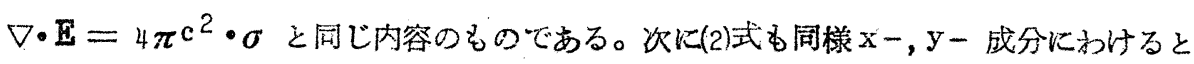

$$
\begin{aligned}
& \frac{m_{e}}{n_{e} c^{2}} \frac{\partial j x}{\partial t}=E_{x}-\frac{1}{n_{e} e} B_{0} \cdot j y-\eta j x \\
& \frac{m_{e}}{n_{e} c^{2}} \frac{\partial j_{y}}{\partial t}=E y+\frac{1}{n_{e} e} B_{0} \cdot j x-\eta j_{y}+\frac{1}{n_{e} e} \frac{\partial p_{e}}{\partial y}
\end{aligned}
$$

となる。こつでpek関して adiabatic compression の仮定をおくと※

$$
\nabla \mathrm{p}_{\mathrm{e}}=-\frac{r_{\mathrm{e}} \kappa \mathrm{T}_{\mathrm{e}}}{\mathrm{e}} \nabla \boldsymbol{\sigma}=-\frac{r_{\mathrm{e}} \kappa \mathrm{T}_{\mathrm{e}}}{4 \pi \mathrm{c}^{2} \mathrm{e}} \nabla \nabla \cdot \mathrm{E},
$$

第 2 因のconfiguration では

$$
\partial_{\mathrm{y}}^{\partial \mathrm{p}_{\mathrm{e}}}=-\frac{\gamma_{\mathrm{e}} \kappa \mathrm{T}_{\mathrm{e}}}{4 \pi \mathrm{c}^{2} \mathrm{e}} \frac{\partial^{2} \mathrm{Ey}}{\partial \mathrm{y}^{2}}
$$

となる。

数式の取扱いとい5観点から云うと、(3)(4)(5)(6)(7)の5式を用い変化はすべて $\operatorname{xp}$ $(k y-\omega t)$ に比例するとして、 $E_{x}, E_{y}, j_{x}, j_{y} \& p_{e}$ がnon-trivia工な解を持つ条 件を求めるとこれがDispersion Relation となる。結果は， $\mathrm{k} \equiv \mathrm{kc} / \omega$ とおくと

$$
\star^{2}=1-\left(\frac{\omega \mathrm{p}}{\omega}\right)^{2}-\frac{1}{1+\mathrm{i} \frac{\nu}{\omega}-\frac{\left(\omega_{\mathrm{ce}} / \omega\right)^{2}}{1+\mathrm{i} \frac{\nu}{\omega}-\left(\frac{\omega \mathrm{p}}{\omega}\right)^{2}-\frac{\gamma_{\mathrm{e}} \kappa \mathrm{Te}}{\mathrm{me}_{\mathrm{e}}} \mathrm{k}^{2}}}
$$

と得られる。こっで通例の如く $\omega_{\mathrm{p}}{ }^{2}=4 \pi \mathrm{n}_{\mathrm{e}} \mathrm{e}^{2} \mathrm{c}^{2} / \mathrm{m}_{\mathrm{e}}, \omega_{\mathrm{ce}}=\mathrm{e} \mathrm{B}_{\mathrm{o}} / \mathrm{m}_{\mathrm{e}}$ \& $\nu=\eta \omega_{\mathrm{p}}{ }^{2}\left(4 \pi \mathrm{c}^{2}\right)^{-1}$ et c.を用いた。この結果は右辺の分母中に含まれる $\mathrm{k}^{2}$ の項を無視 すれば、今迄近似的に成立つとして示されていたるの※゙と全く一致する。それ故眯密波の影響 は 1 k対して $r_{\mathrm{e}} \kappa \mathrm{T}_{\mathrm{e}} /\left(\mathrm{m}_{\mathrm{e}} \mathrm{c}{ }^{2}\right)$ の order できいていることがわかる。数万度程度の， Cold plasma ならばこのfactorは1 $0^{-5}$ 程度で無視してもよい。

Me chanism と直結した観方ということからいえば、次の導き方がよりわかり易いであろ

脚註 ※ loc. cit., p. 59

※ f or example,S. Tanaka ; 核融合研究 4 出 550 ('60) 
5。即ち空間電荷を導入した方がはつきりする。

(2)式のDivergence をとつてみる。 $\nabla n_{e} \ll n_{e}, \nabla \times B=0$ を留意して、 $\nabla \cdot j=-\frac{\partial \sigma}{\partial t}$ 及び $\nabla \cdot \mathbf{E}=4 \pi \mathrm{c}^{2} \cdot \sigma$ で $\sigma$ を導入すると、

$$
\frac{\partial^{2} \sigma}{\partial \mathrm{t}^{2}}=\frac{\gamma_{\mathrm{e}} \kappa \mathrm{T}_{\mathrm{e}}}{\mathrm{m}_{\mathrm{e}}} \nabla^{2} \sigma-\nu \frac{\partial \sigma}{\partial \mathrm{t}}-\omega_{\mathrm{p}}{ }^{2} \sigma-\omega_{\mathrm{ce}} \frac{\partial \mathrm{j}_{\mathrm{x}}}{\partial \mathrm{y}}
$$

となる。右边最後の項はj $\times$ B 強制されている柾密波動をあらわしている。第2図のconf i g u r a t i on からわかる様に、 $\nabla \cdot \mathrm{j}=-\partial \sigma / \partial \mathrm{t}$ から $\sigma$ は $\mathrm{j} \mathrm{y}$ できる故先の(6)式が丁度この(9)式となるものである。同様に

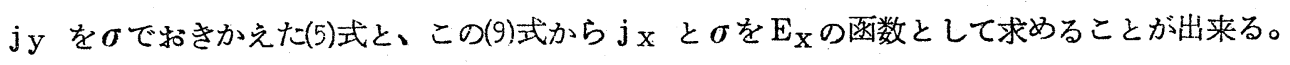

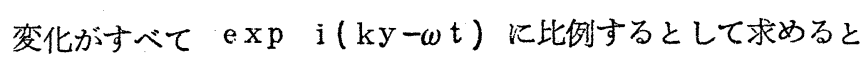

$$
j x=\frac{i}{\omega} \frac{\omega_{p}^{2}}{4 \pi^{2}}\left[1+\frac{i \nu}{\omega}-\frac{\left(\frac{\omega c e}{\omega}\right)^{2}}{1+\frac{i \nu}{\omega}-\left(\frac{\omega p}{\omega}\right)^{2}-\frac{\gamma_{e} \kappa T_{e}}{m_{e} c^{2}} k^{2}}\right]^{-1} E_{x}
$$

となる。これが $E_{X} に$ follow する currentである。

故に(3)式としての

$$
\vec{k}^{z}=1+i \frac{4 \pi c^{2}}{\omega} \frac{j x}{E x}
$$

に代入すると、Dispersion ReIation として(8)式方求まる。それ故電磁波としての $\mathrm{E}_{\mathrm{x}}$ は $\mathrm{j} \mathrm{x}$ 及び jy を生ずるが その中 jy は蹯密波となる。この蹯密波はjxからenergy を得ているので、逆に $j_{x}$ も当然その影響を受ける。その結果の $\mathrm{jx}$ が Ex K respons, e する polarization current であつて、これが $E_{X}$ の伝播を disturb するすの となつている。 